\title{
Visual Map Development: Bidirectional Signaling, Bifunctional Guidance Molecules, and Competition
}

\author{
David A. Feldheim ${ }^{1}$ and Dennis D. M. O'Leary ${ }^{2}$ \\ ${ }^{1}$ MCD Biology, University of California, Santa Cruz, Santa Cruz, California 95064 \\ ${ }^{2}$ Molecular Neurobiology Laboratory, The Salk Institute, La Jolla, California 92037 \\ Correspondence: doleary@salk.edu and feldheim@biology.ucsc.edu
}

Topographic maps are a two-dimensional representation of one neural structure within another and serve as the main strategy to organize sensory information. The retina's projection via axons of retinal ganglion cells to midbrain visual centers, the optic tectum/superior colliculus, is the leading model to elucidate mechanisms of topographic map formation. Each axis of the retina is mapped independently using different mechanisms and sets of axon guidance molecules expressed in gradients to achieve the goal of representing a point in the retina onto a point within the target. An axon's termination along the temporal-nasal mapping axis is determined by opposing gradients of EphAs and ephrin-As that act through their forward and reverse signaling, respectively, within the projecting axons, each of which inhibits interstitial branching, cooperating with a branch-promoting activity, to generate topographic specific branching along the shaft of the parent axons that overshoot their correct termination zone along the anterior-posterior axis of the target. The dorsal-ventral termination position is then determined using a gradient of ephrin- $B$ that can act as a repellent or attractant depending on the ephrin-B concentration relative to EphB levels on the interstitial branches to guide them along the medial-lateral axis of the target to their correct termination zone, where they arborize. In both cases, axon-axon competition results in axon mapping based on relative rather than absolute levels of repellent or attractant activity. The map is subsequently refined through large-scale pruning driven in large part by patterned retinal activity.

\section{TOPOGRAPHIC MAPPING: THE VISUAL SYSTEM}

The human brain contains billions of neurons that make large numbers of synaptic connections. It is the organization of these connections that is responsible for our ability to perceive the outside world and serves as the framework for higher cognitive functions such as learning, memory, thought, and emotion. One method the CNS employs to organize connections is the use of topographic maps, meaning that the neighbor-neighbor relationships of neurons in a projection field are maintained when choosing synaptic partners in a target area. Topographic maps are used by most CNS

Editors: Marc Tessier-Lavigne and Alex L. Kolodkin

Additional Perspectives on Neuronal Guidance available at www.cshperspectives.org

Copyright (C) 2010 Cold Spring Harbor Laboratory Press; all rights reserved; doi: 10.1101/cshperspect.a001768

Cite this article as Cold Spring Harb Perspect Biol 2010;2:a001768 
projections and it is thought that they ensure the spatial identity of a stimulus as it is transferred to different regions of the brain for processing. Because of the experimental accessibility of visual areas in the brain, and the fact that connectivity can be analyzed both anatomically and functionally, the vertebrate visual system has historically been the model system used by both experimentalists and theoretical neuroscientists to understand how topographic maps form during development.

Visual information is transferred from the retina to multiple areas in the brain with the spatial information of the visual field maintained in each target (Fig. 1). In mammals, the retina sends projections to several targets that are involved in image and nonimage forming visual behaviors. Two of the main targets of the retina are the superior colliculus (SC, analogous to the optic tectum [OT] in lower vertebrates), a midbrain structure used to control head and eye movements, and the dorsal lateral geniculate nucleus (dLGN) in the dorsal thalamus. The dLGN in turn projects to the primary visual cortex (V1) in the posterior cerebral cortex, which subsequently projects to several "higher" visual areas responsible for conscious vision. Each component of the visual system is mapped topographically (Lewin 1994; Udin and Fawcett 1988) (Fig. 1).

\section{CHEMOAFFINITY HYPOTHESIS}

Determining the mechanisms of topographic mapping has been a focus of neuroscience since the middle of the past century. The initial insights came from studies of the re-establishment of orderly connections in regenerating axonal projections in adult amphibians and fish. These studies, and in particular the classic behavioral and anatomical studies performed by Roger Sperry on the specificity of regenerating axonal projections from retinal ganglion cells (RGCs) to the OT in adult frogs, led to the formulation of the chemoaffinity hypothesis. Sperry interpreted his findings as indicative of chemospecificity; i.e., molecular tags on projecting axons and their target cells determine the specificity of axonal connections within a topographic map through a positive lock and key strategy (Sperry 1951). Sperry progressively elaborated on the chemoaffinity hypothesis by proposing that the molecular tags could be distributed in complementary gradients that

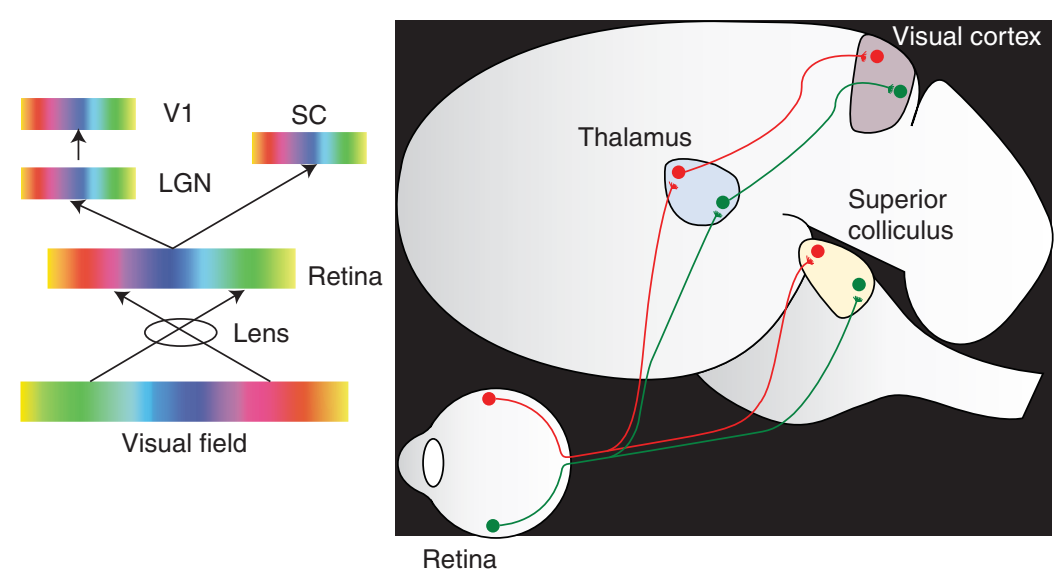

Figure 1. Visual areas in the brain are mapped topographically. In the mammalian visual system, photoreceptors in the retina detect photons and transfers this information to multiple visual areas in the brain, including the superior colliculus (SC) in the midbrain and the dorsal lateral geniculate nucleus (dLGN) in the thalamus. The dLGN then transfers this information to the primary visual cortex (V1). Each of the projections is mapped topographically such that neighboring inputs in the visual field (shown as different colors) maintain their relationships as information is transferred, creating a visuotopic map in each processing area. 
mark corresponding points in both the projecting and target neural populations (Sperry 1963). Each point in the OT has a unique molecular address determined by the graded distribution of topographic guidance molecules along its two axes, and similarly each RGC has a unique profile of receptors for those molecules that would result in a position-dependent, differential response to them by RGC axons.

\section{IDENTIFICATION OF TOPOGRAPHIC GUIDANCE ACTIVITIES}

The key properties of topographic mapping molecules were defined by Friedrich Bonhoeffer and colleagues using an in vitro assay that recapitulated some aspects of retinotectal mapping in vivo. In their assay, the so-called membrane stripe assay, RGC axons are given a choice between growing on alternating lanes of anterior and posterior OT membranes. They found that temporal axons show a strong preference to grow on their topographically appropriate, anterior membranes, whereas nasal RGC axons showed no preference. They further showed that this growth preference was because of the presence of a GPI-linked protein expressed on posterior membranes that acted as an axon repellent (Walter et al. 1987a,b). This work was very exciting as it showed that understanding the molecular basis of axon guidance was possible using in vitro assays, thereby facilitating their isolation. Further, this was not only the first demonstration of a molecular topographic guidance activity, but was the initial finding that axon guidance activities can function as repellents.

Despite a massive effort that spanned decades, the characterization of this activity did not come until the mid-1990s with the discovery of ELF-1 (Eph Ligand Family-1) by HwaiJong Cheng and John Flanagan (Cheng and Flanagan 1994, Cheng et al. 1995; Nakamoto et al. 1996) and RAGS (repulsive axon guidance signal) by Uwe Drescher and Friedrich Bonhoeffer (Drescher et al. 1995). These two related GPI-linked proteins are members of the ephrin gene family, and have been renamed ephrin-A2
(ELF-1) and ephrin-A5 (RAGS) (Eph Nomenclature Committee 1997). Both are expressed in a low to high AP gradient in the OT of embryonic chickens, and are ligands of the receptor tyrosine kinase, EphA3 (originally named MEK4), which is expressed in a high to low TN gradient by RGCs in the retina of embryonic chickens (Cheng et al. 1995). Through the use of the membrane stripe assay and by ectopic expression in embryonic chick OT, ephrinA2 (Nakamoto et al. 1996) and ephrin-A5 (Drescher et al. 1995; Monschau et al. 1997) were shown to be axon repellents and found to meet functional criteria for topographic guidance molecules, including differential responses of RGC axons to them. Subsequently, targeted deletions of ephrin-A5 (Fri-sen et al. 1998) and ephrin-A2 (Feldheim et al. 2000) showed that they are required for the proper topographic mapping of RGCs in the mouse SC, the mammalian homolog of the OT.

\section{STAGES OF MAP DEVELOPMENT AND MAJOR DISTINCTIONS BETWEEN COLD-BLOODED AND WARM-BLOODED VERTEBRATES IN MAP DEVELOPMENT}

Determining the behaviors exhibited by RGC axons as they establish topographic connections within their target is critical for defining both the function and the minimum requirements for topographic guidance molecules in map development. The dogma derived from studies of cold-blooded vertebrates such as frogs and fish was that the topographically directed targeting of axonal growth cones was the primary mechanism of map development. However, through the use of high resolution axon tracers, such as DiI and DiO, introduced in the late 1980s, Dennis O'Leary and colleagues showed that RGC axons in warm-blooded vertebrates, such as rodents and chickens, use very different strategies of axon targeting to develop topography. These findings not only led to a reevaluation of mechanisms of axon guidance during map development, but also had significant implications for the function of topographic guidance molecules in this process. 
D.A. Feldheim and D.D.M. O'Leary

In frogs and fish, the growth cone of the primary RGC axon extends directly to the topographically correct location of its future termination zone (TZ), stops and undergoes arborization of the distal part of the primary axon through the formation of short terminal branches from the growth cone and near its base, a behavior termed "back-branching," which cooperate to form a terminal arbor (Fujisawa, 1987; Harris et al. 1987; O'Rourke et al. 1990; Kaethner and Stuermer 1992). Development of retinotopic maps in chick OT (Nakamura and O'Leary 1989; Yates et al. 2001) and rodent SC (Simon and O'Leary 1990, 1992a,b,c; Hindges et al. 2002) however is a distinct multistep process. Initially, the primary growth cones of RGC axons enter the target at its anterior end and extend posteriorly past the location of their future TZ (Nakamura and O'Leary 1989; Simon et al. 1992a,b; Yates et al. 2001). Interstitial branches then start forming along the length of the axon shaft far behind the growth cone with the highest percentage of branches forming at the AP position of the future TZ. Once formed, the branches preferentially extend along the LM axis toward their future TZ (Nakamura et al. 1989; Simon et al. 1992c; Hindges et al. 2002; McLaughlin et al. 2003b) (Fig. 2).

The final phase of map development involves a large scale remodeling that occurs over a few days and eliminates major segments of the primary axon distal to the AP position of the appropriate TZ, as well as branches and arbors that formed at topographically incorrect positions (Nakamura and O'Leary 1989; Simon et al. 1990, 1992b; Hindges et al. 2002) resulting

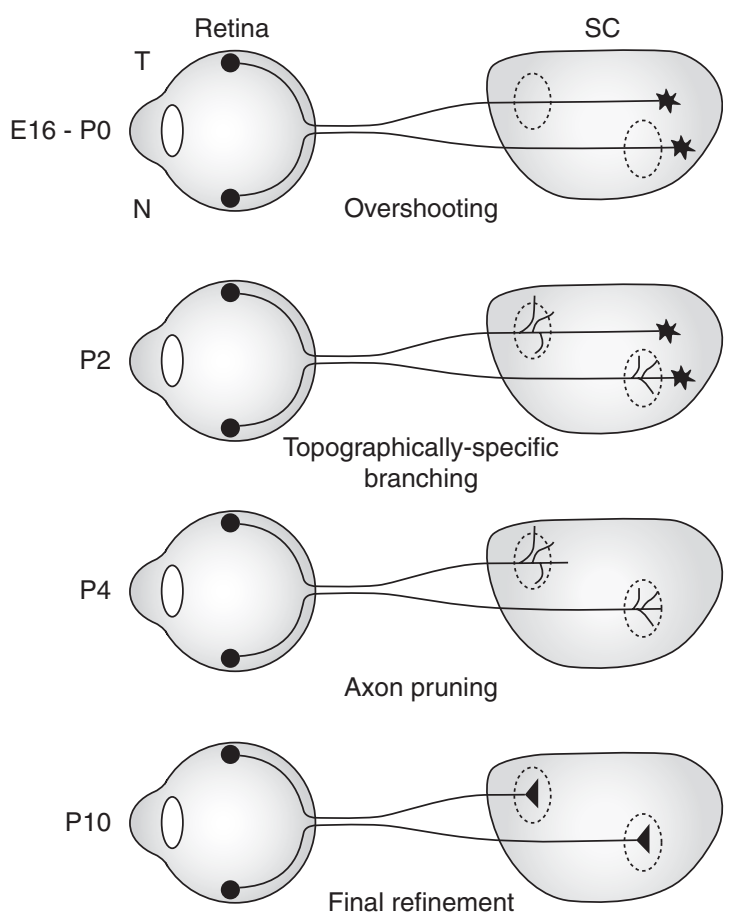

Figure 2. Developmental stages in mapping temporal-nasal retinal axis on anterior-posterior axis of colliculus/ tectum in mice and chicks. Initially RGC axons enter the SC at the anterior end and project to the posterior SC overshooting their topographically appropriate termination zone (dashed circles). Then branching occurs from the axon at the topographically specific location followed by pruning of the posterior axon. At later stages the branches are stabilized, and refine to form strong synapses. In mice this process starts late in embryogenesis and lasts through the first week of life (E, embryonic day post conception; P, postnatal). 
in a topographically refined projection. Recent advances have provided insights into this remodeling process in chicks and mice. The segments of primary axons and axon branches are rapidly eliminated by a process that morphologically resembles Wallerian degeneration (Nakamura and O'Leary 1989; Hoopfer et al. 2006), but is mechanistically distinct (Hoopfer et al. 2006). This naturally-occurring axon elimination occurs independent of RGC death (O'Leary et al. 1986; Nakamura and O'Leary 1989; Simon and O'Leary 1992c) and is mediated by the selective activation of a caspase-6dependent signaling system within the ill-fated axons, which is distinct from a caspase-3-dependent system that results in apoptosis of the RGC cell body (Nikolaev et al. 2009). Little is known about the triggers for axon elimination or the mechanism that determines the selectivity of the elimination process other than a role for correlated activity in determining axons to be eliminated versus retained (McLaughlin et al. 2003a).

\section{EPHS AND EPHRINS: BIFUNCTIONAL AND BIDIRECTIONAL SIGNALING}

Eph receptors and ephrin ligands were not only the first topographic guidance molecules to be discovered, but they remain the dominant molecular players in controlling the development of topographically organized projections, not only in the visual system, but also in many other axonal projection systems in vertebrates. Only a few other proteins have been implicated in mapping, including the morphogen Wnt3 and its receptors Ryk and Frizzled implicated in DV mapping, the neurotrophin BNDF and its receptors TrkB and p75 neurotrophin receptor (NTR), and the cell adhesion molecules, L1 and CHL1, which have all been reported to influence mapping possibly indirectly through modulating ephrin-A function (described later).

The Eph family, the largest family of RTKs, and their ephrin family of "ligands", are comprised of 14 Ephs and 8 ephrins in mouse and 15 Ephs and 9 ephrins in chicks (Eph Nomenclature Committee 1997). Ephs and ephrins are separated into A and B subclasses based on homology, within which receptor-ligand binding and activation is promiscuous (Kullander and Klein 2002). All Ephs, as well as ephrin-Bs, are transmembrane proteins, whereas ephrinAs are tethered to the cell membrane by a GPIlinkage. A small degree of crosstalk occurs between subclasses, with the most notable example being EphA4 binds ephrin-B1 and ephrin-B2.

Eph/ephrin signaling can be bifunctional, acting either to attract or to repel, even within the same axonal population at the same time in development in a context-dependent fashion (McLaughlin et al. 2003b; Marquardt et al. 2005). Ephs and ephrins can also signal bidirectionally into either the Eph or ephrin expressing cell or axon (Egea and Klein 2007). This was first shown for the transmembrane ephrin-Bs, but has now also been shown for the GPI-linked ephrin-As. As described below, EphAs and ephrin-As act bidirectionally in mapping the $\mathrm{TN}$ retinal axis along the AP axis of the OT/ SC through association with a transmembrane signaling protein, the p75NTR. EphBs and ephrin-Bs act both bidirectionally and bifunctionally in mapping the DV retinal axis along the DV axis of the OT or the analogous ML axis of the SC.

\section{EPHAs AND EPHRIN-As IN TEMPORAL-NASAL TO ANTERIOR- POSTERIOR MAPPING}

Ephs and ephrins are expressed throughout the vertebrate visual system. Although speciesspecific differences are apparent in the expression patterns and the specific family members expressed, the basic theme is constant across vertebrates. Here we focus on the expression patterns in the retinotectal and retinocollicular projections of chicks and mice (see McLaughlin and O'Leary 2005 for schematic presentation of expression patterns in retina and OT/SC and all pertinent references). In both species, ephrin-A2 and ephrin-A5, and a distinct subset of their EphA receptors, are expressed in complementary graded patterns in the retina and the chick OT and mouse SC. EphAs are expressed in a high to low TN gradient by RGCs, and 
D.A. Feldheim and D.D.M. O'Leary

A
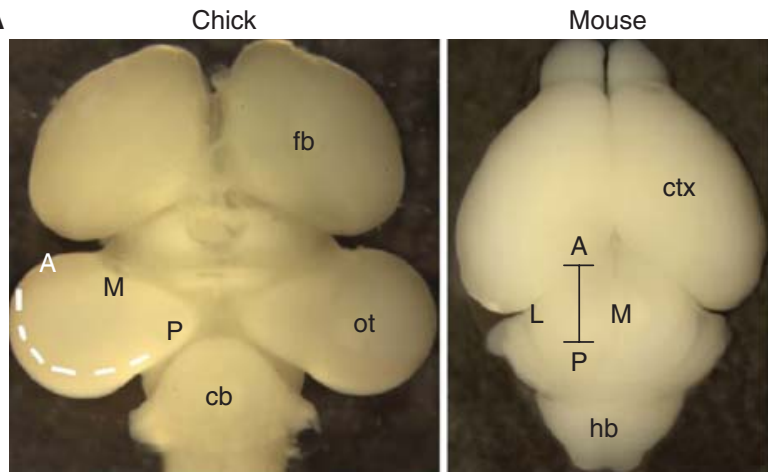

Mouse/Chick

B

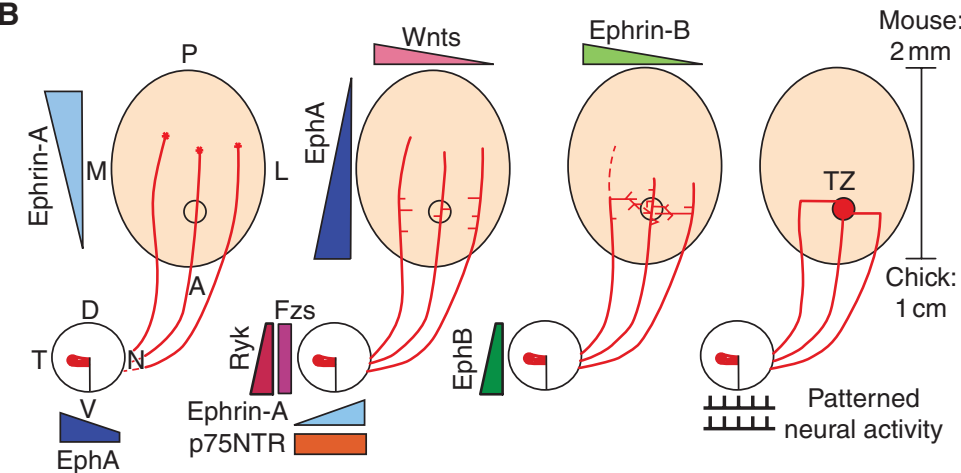

C

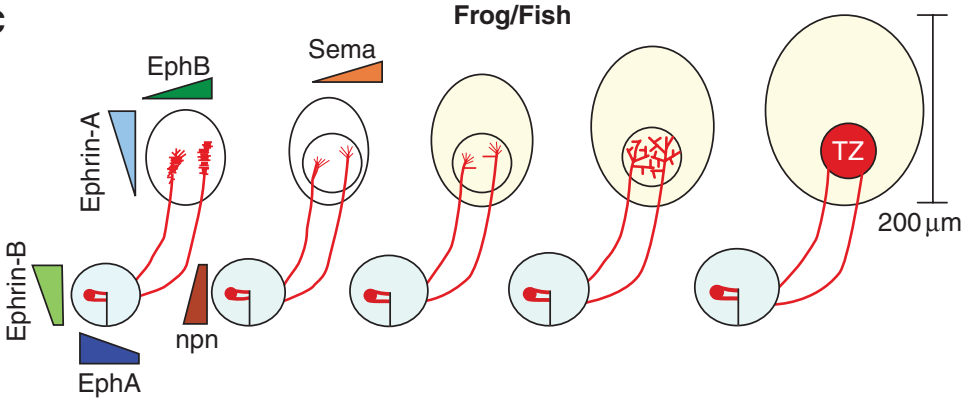

Figure 3. Substantial size differences in midbrain targets and distinct mechanisms of map development exhibited by model systems. (A) Photographs are of the primary model systems currently used to study retinocollicular/ retinotectal map development, taken at critical ages during map formation. Photos are at the same scale. Photos of chick and mouse show dorsal surface of brain. The white dashed line on the chick optic tectum (ot) indicates the anterior $(\mathrm{A})$-posterior $(\mathrm{P})$ axis. The bracket on the mouse midbrain shows the extent of the AP axis of the superior colliculus (SC); the extent of the Lateral (L)-Medial (M) axis is marked by L and M. Paired photos for Xenopus (frog) and zebrafish show lateral (left) and dorsal (right) views: the AP extent of the optic tectum (OT) in each is marked by small white bars adjacent to the brain. The dramatic differences in target size between the warm-blooded vertebrates (chick and mouse) relative to the cold-blooded vertebrates (frog and fish) may underlie the significant differences in mechanisms employed by RGC axons to develop retinotopic maps in them. ( $B$ and $C$ ) Mechanisms and molecules controlling retinotopic mapping in $(B)$ mouse and chick and $(C)$ frog and zebrafish. The names and distributions of molecules and activities shown in vivo to control the mapping mechanisms exhibited at each stage are indicated. The gradients may represent the consensus distribution for a combination of related molecules (e.g., EphAs), which are not listed individually because of distinctions in the individual members expressed and the precise distributions between species. Molecules and activities other than those listed are likely to participate in topographic mapping. (See facing page for legend.) 
ephrin-As are expressed in a low to high AP gradient in OT/SC, whereas ephrin-As and EphAs are expressed in opposing gradients by RGCs and in the OT/SC, respectively. This basic theme is reiterated at higher levels of the visual system, for example, in the connections between the primary visual cortex and the dLGN and SC in mice (Cang et al. 2005a; Torii and Levitt 2005).

In chick, ephrin-A2 is expressed in an increasing AP gradient across the entire OT, and ephrin-A5 is expressed in a steeper AP gradient, largely limited to the posterior OT. Together they combine to form an increasing gradient of ephrin-As across the AP axis. RGCs express EphA3, EphA4, and EphA5, but only EphA3 is expressed in a gradient, a high to low TN graded pattern (Cheng et al. 1995; Monschau et al. 1997). Because temporal retina with high levels of EphA3 maps to anterior OT with low levels of ephrin-As, and vice versa, ephrin-A2 and ephrin-A5 were predicted to act as axon repellents that more strongly affect temporal axons than nasal axons, which was confirmed by in vitro and in vivo studies (Nakamoto et al. 1996; Monschau et al. 1997). Experiments employing membrane stripe and growth cone collapse assays using membranes from transfected cell lines show that both ephrin-A2 and ephrin-A5 preferentially repel temporal axons, and that at the appropriate concentrations, retinal axons show a graded temporal to nasal response to ephrin-A5, but curiously not to ephrin-A2 . Further, the influence of ephrin-As on RGC axons appears to transition from repulsion to attraction via distinct mechanisms at very low concentrations of ligand (Hansen et al. 2004). In vivo, temporal axons specifically avoid ectopic patches of ephrin-A2 overexpressed in anterior OT. These studies suggest that the interaction of EphA3 with ephrin-A2 and ephrin-A5 could determine the specificity of RGC projections along the AP tectal axis.

The basic theme described above for chicks is similar to that in mice. In the mouse SC, ephrin-A2 and ephrin-A5 combine to form an overall increasing AP gradient of ephrin-As (Frisen et al. 1998). However, their pattern of expression in the SC differs substantially from chick OT: Ephrin-A5 is expressed in an increasing AP gradient across the SC, resembling ephrin-A2 in chick tectum, whereas ephrin-A2 is expressed at high levels in a broad domain centered on midposterior SC and shows a graded decline to low or no expression in the anterior third and far-posterior SC (Fig. 3). Ephrin-A3 is also expressed in the SC but at low uniform levels across the SC (Pfeiffenberger et al. 2006). The expression of EphA receptors by RGCs also differs between chick and mouse. In mouse, EphA3 is not expressed by RGCs, EphA4 is expressed uniformly, and both EphA5 and EphA6 are expressed in a high to low TN gradient (Brown et al. 2000; Feldheim et al. 2000).

The graded expression of ephrin-As and their differential repulsion of temporal versus nasal RGC axons strongly implicated them as topographic guidance molecules, which was subsequently confirmed by the analysis of mice with targeted deletions of ephrin-A5 (Frisen et al. 1998) and ephrin-A2 (Feldheim

Figure 3. (Continued) (B) In mouse and chick RGC axons enter the OT/SC over a broad LM extent and significantly overshoot their future termination zone (TZ, circle). Interstitial branches form de novo from the axon shaft around the correct anterior-posterior $(\mathrm{A}-\mathrm{P})$ position of their future TZ. Branches are directed along the lateral-medial $(\mathrm{L}-\mathrm{M})$ axis of the OT/SC toward the position of the future TZ, in which they arborize in a domain encompassing the forming TZ. The broad, loose array of arbors is refined to a dense TZ in the topographically appropriate location. $(C)$ In frogs and fish the RGC growth cone extends to the TZ in which it forms a terminal arbor through a process of terminal branching of the growth cone and backbranching immediately behind the growth cone. The tectum expands as terminal arborizations elaborate and refine into a mature TZ. See text for further description, function of topographic guidance molecules and patterned activity, and references. cb, cerebellum; ctx, cortex; D, dorsal; fb, forebrain; hb, hindbrain; N, nasal; T, temporal; V, ventral. (Modified from McLaughlin et al. 2003c [ (C) Elsevier].) 
D.A. Feldheim and D.D.M. O'Leary

et al. 2000). The mapping of RGC axons in the SC of ephrin-A5 null mice is topographically aberrant in a manner consistent with the loss of ephrin-A5 and the maintained expression of ephrin-A2. Topographic mapping defects in ephrin-A2/A5 double knockout mice are more severe than in either ephrin-A single knockouts (Feldheim et al. 2000). Surprisingly, though, in ephrin-A2/A5 double knockout mice, temporal RGC axons form a TZ, albeit smaller, in anterior SC at approximately the correct position, suggesting the action of other molecules and/or mechanisms. This led to the finding that ephrin-A3 is expressed in mouse $\mathrm{SC}$ at low levels uniformly across its AP axis. Mice with a triple knockout of ephrin-A2, -A3 and -A5 show even stronger mapping defects. When the ephrin-A2/A5 double knockout is combined with mice that lack patterned RGC activity (discussed in a later section), topography is virtually completely lost (Pfeiffenberger et al. 2006; Cang et al. 2008b) (Fig. 4).

The final evidence to definitively establish that ephrin-As mediate the repulsion of RGC axons by forward signaling through EphA receptors comes from genetic studies of EphAs. Expressing a kinase dead EphA3 receptor in chick temporal RGCs as a dominant negative for endogenous EphA3 results in their mapping posterior to their correct sites in the OT and reduces their responsiveness to ephrin-A mediated repellents in vitro (Feldheim et al. 2004). Similar in vivo and in vitro findings are obtained from mice with a targeted deletion of EphA5, consistent with it mediating a repellent activity of ephrin-As preferential for temporal RGC axons through forward signaling (Feldheim et al. 2004). A particularly intriguing study that revealed unique EphA function employed a gain-of-function strategy that took advantage of the features that ephrin-As bind and activate with similar efficacy most EphA receptors, and that EphA3 is not expressed by RGCs in mice. By producing a knockin of an EphA3-IRES construct into the 3' UTR of the Isl2 gene, mice were generated in which EphA3 was ectopically expressed in about half of the overall RGC population distributed uniformly across the retina, thus producing two subpopulations of RGCs, one which has the wild-type gradient of EphA receptors (EphA5 and EphA6), and one with an elevated gradient of overall EphA expression (Brown et al. 2000). In these mice, the projection of the EphA3

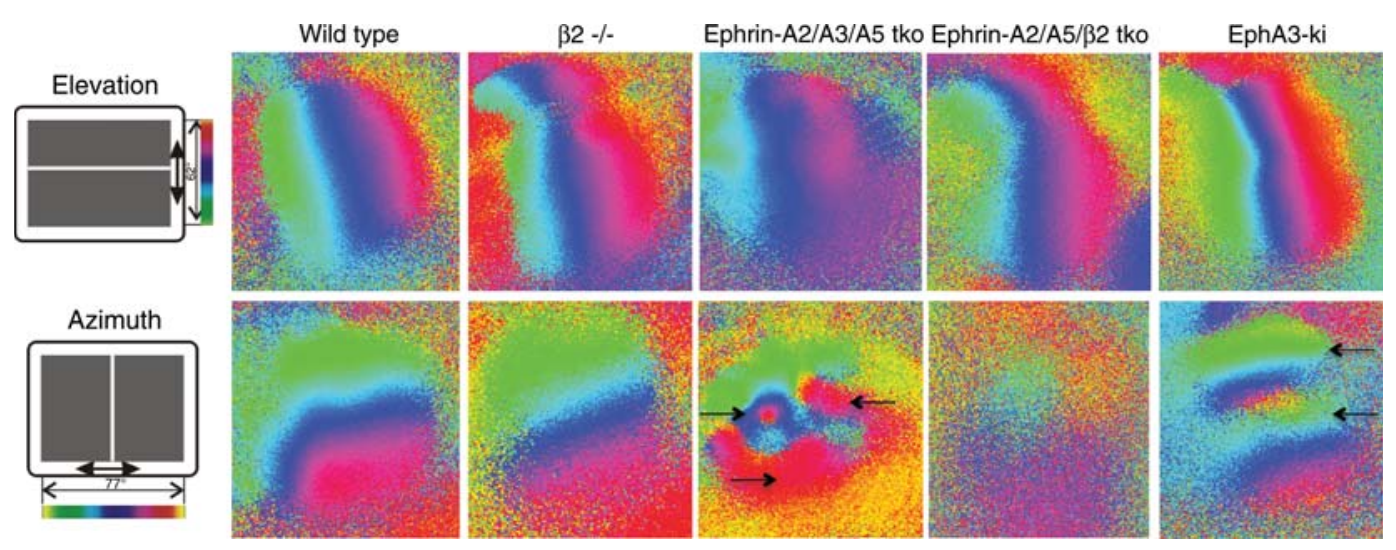

Figure 4. Functional imaging of adult SC in wild type and mutant mice. Top panels show that the D-V retinal projection onto the medial-lateral axis of the SC is largely normal in the mice indicated. Bottom panels show that the N-T retinal projections map onto the anterior-posterior axis of the SC. Note that ephrin-A tkos have a patchy map (arrows highlight red regions [nasal axon mapping regions] that are noncontiguous), whereas ephrin-A2 /A5/ $\beta 2$ tkos have no map, specifically along the N-T mapping axis. Amazingly, the EphA3-ki mouse maps are duplicated within the SC (arrows mark regions of duplication). (Adapted from Cang et al. 2005b, 2008b; Triplett et al. 2009.) 
RGCs is compressed to the anterior half of the $\mathrm{SC}$, indicating that the overall level of EphA receptors dictates the degree to which an RGC axon is repelled by ephrin-As. Surprisingly, though, the projection of the wild type RGCs is compressed to the posterior half of the SC, a finding that suggests the action of competitive interactions with the EphA3 RGCs that excludes the wild type RGCs from anterior SC. Thus, the mapping of the two RGC subpopulations is not determined by the absolute level of EphA receptor signaling, but instead is plastic and strongly influenced by the relative difference in EphA signaling. This conclusion was tested by crossing the EphA3-KI line with the EphA4 knockout mice: The offspring of this cross have a greater relative difference in overall EphA levels between the EphA3-KI and wild-type RGCs, although absolute differences are unchanged (Reber et al. 2004). As predicted, a greater separation is observed between the maps of the two RGC populations, corroborating the conclusion of Brown et al. (2000) that the relative difference in EphA receptor levels rather than absolute levels among competing RGCs is a critical parameter in establishing maps (Reber et al. 2004). The findings of Brown et al. (2000) also reveal a hierarchy in the mechanisms for generating topographic maps, and led to the conclusion that molecular axon guidance information, such as that signaled by ephrin-As and EphAs, can over come activity-dependent patterning mechanisms that are based on near neighbor relationships and correlated activity.

\section{TEMPORAL-NASAL TO ANTERIOR- POSTERIOR RETINOTOPIC MAPPING ACHIEVED THROUGH SPECIFIC INTERSTITIAL BRANCHING}

In chicks and rodents, the critical event in retinotopic mapping is the topographic-specific formation of interstitial branches. These branches form from the shaft of the primary axon in the vicinity of the future $\mathrm{TZ}$, which can be far (millimeters or more) behind the growth cone when branches begin to bud (Nakamura and O'Leary 1989; Simon and O’Leary 1992a,b; Yates et al. 2001; Hindges et al. 2002; also see Bastmeyer and O'Leary 1996). The requirements for topographic guidance molecules necessary to account for the observed AP specificity in interstitial branching are more complex than the requirements for simply halting growth cone advance in which a single low to high AP repellent activity can account for topographic growth cone targeting (Fig. 5A,B) (Nakamoto et al. 1996). In contrast, at least two distinct activities are required along the AP axis to account for topographic-specific interstitial branching: One that accounts for the high density of primary interstitial branches forming along the axon shafts in the vicinity of the AP position of the future TZ, and another that can explain the lack of interstitial branches along segments posterior and anterior to the future TZ (O'Leary et al. 1999; Yates et al. 2001, 2004).

Models that can account for T-N branching specificity have been proposed, and they include a model based on parallel gradients of a branch repellent (or inhibitory) activity and a branch promoting activity, and also a model with opposing repellent gradients that inhibit branching and cooperate with a branch promoter (O'Leary et al. 1999; Yates et al. 2001; McLaughlin and O'Leary 2005) (Fig. 5C,D). The distribution of these activities varies with their sign (attractant or repellent), but regardless, centering the distribution of branches around the future $\mathrm{TZ}$ requires one activity that limits branching posterior to the TZ and another activity that limits branching anterior to the TZ (Yates et al. 2001, 2004). This is a minimum requirement to account for the observed branching behavior of RGC axons in vivo in the rodent SC or the chick OT- of course, more activities could be layered on these to add redundancy and reinforce the molecular control of the process.

The molecular framework required for each model is present in the OT/SC. In both models, the paucity of branches posterior to the correct $\mathrm{TZ}$ is controlled by a low to high AP repellent gradient because of EphA-ephrin-A forward signaling that acts to inhibit interstitial branching along the axon shaft at levels of forward signaling suprathreshold for branch inhibition found posterior to the correct TZ. Evidence 
D.A. Feldheim and D.D.M. O'Leary

A
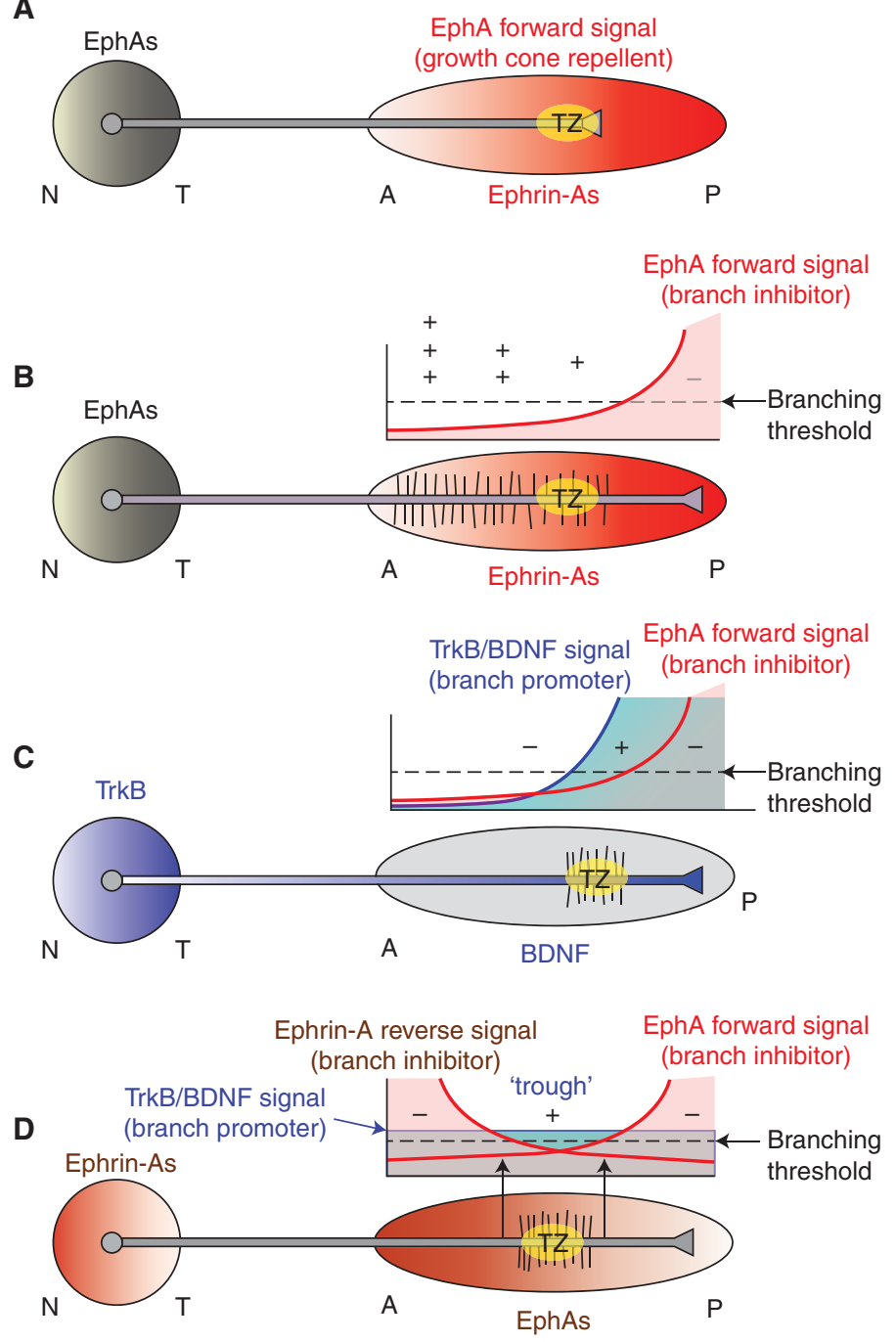

Figure 5. Regulation of topographic-specific interstitial branching along anterior-posterior axis of tectum/ colliculus: the critical determinant of retinotopic mapping. Shown are models based on known expression patterns of EphAs, ephrin-As, TrkB, and BDNF, their influences on RGC axons, and their proposed roles or deficiencies in development of topographic maps. All models have as recurring theme the graded repellent activity that preferentially affects temporal RGC axons and is achieved by EphA forward signaling. (A) EphA is expressed in a high to low temporal $(\mathrm{T})$ to nasal $(\mathrm{N})$ gradient by RGCs, and ephrin-As in a low to high anterior (A) to posterior (P) gradient in the optic tectum (OT)/superior colliculus (SC). This receptor-legend pairing generates through EphA forward signaling a high to low AP gradient of repellent activity that preferential affects temporal RGC axons, and is in principle sufficient to topographically guide RGC axonal growth cones along the AP axis to their appropriate terminal zone (TZ). This mapping mechanism is adequate in lower vertebrates. $(B)$ However, a single repulsive gradient cannot generate the topographic interstitial branching of RGC axons along the AP axis observed in chicks and rodents, because branching would occur at a greater frequency more anterior to the TZ. This is not observed in vivo-branching is focused on the $\mathrm{AP}$ position of the TZ and is lower both anterior and posterior it. $(C)$ In principal, topographic-specific interstitial branching could be achieved by a model with a gradient of molecules with branch promoting activities that cooperate with the EphA forward signaling inhibition of branching. (See facing page for legend.) 
for this mechanism is fairly direct. In vitro studies using a version of the membrane stripe assay modified to analyze branching show that ephrin-As inhibit interstitial branch formation preferentially along temporal RGC axons (Roskies and O'Leary 1994; Yates et al. 2001). In vivo, local inactivation of ephrin-As using the CALI technique results in enhanced local branching in the OT (Sakurai et al. 2002). These findings indicate that the low to high AP gradient of ephrin-As in the OT/SC produces a level of ephrin-As along RGC axons posterior to their correct $\mathrm{TZ}$ that inhibits their branching, and thereby helps generate the topographic bias in branching along the AP axis of the OT/SC observed in vivo (Fig. 5) (Simon et al. 1992a; Yates et al. 2001).

In the first model, the paucity of branches anterior to the correct $\mathrm{TZ}$ is controlled by a low to high AP gradient of a signal that promotes branching along each RGC axon, with the branching activity only exceeding the branch inhibition activity in the vicinity of the $\mathrm{TZ}$ (Fig. 5C). BDNF signaling through TrkB has been proposed to be a candidate for this branchpromoting signal (O'Leary et al. 1999; Yates et al. 2001; McLaughlin and O'Leary 2005). Consistent with this suggestion, BDNF is expressed by the appropriate OT cells, $\operatorname{TrkB}$ is present in a high to low TN gradient on RGC axons, and BDNF promotes interstitial branching in vitro though a mechanism dependent on TrkB signaling (Choi 1998; Choi et al. 2000).

In the second model, the paucity of branches anterior to the $\mathrm{TZ}$ is because of a high to low $\mathrm{AP}$ repellent gradient generated by EphA-ephrin-A reverse signaling, that opposes the forward signaling gradient (Fig. 5D). This gradient acts to inhibit interstitial branching along the axon shaft anterior to the correct TZ. In support of this model, recent studies have indicated that ephrin-A-expressing axons are repelled by EphAs in vitro, and ephrin-A5 and EphA7 mutant mice have mapping phenotypes consistent with this model (Feldheim 2000; Rashid et al. 2005; Lim et al. 2008). In ephrin-A5 mutants, nasal axons that normally express high levels of ephrin-A5 and branch at posterior SC positions, branch at more anterior positions, consistent with the idea that these axons are less sensitive to EphA repulsion when deficient for ephrin-A5 (Feldheim 2000). EphA7 mutant mice (EphA7 is expressed in a high to low AP gradient in the SC, but is not expressed by RGCs) also have topographic mapping defects, with some nasal axons terminating at the anterior end of the SC (Rashid et al. 2005). Because ephrin-As are anchored to the cell membrane by a GPI linkage and lack an intracellular domain, to transduce a signal they must associate with transmembrane proteins capable of activating intracellular signaling pathways. Recent studies

Figure 5. (Continued) Branching is prevented posterior to the correct TZ by ephrin-A repellent activity mediated by EphA forward signaling, and does not occur anterior to the correct TZ because the branch promoting activity is subthreshold. Branching occurs at the AP position in which the branch promoter is suprathreshold and the branch inhibitor is subthreshold. TrkB, in a similar distribution to EphAs in the retina (and/or, if TrkB were graded along each RGC axon), and BDNF in the OT/SC have the appropriate activities to act as the graded branch promoter, and cooperate with the graded branch inhibitor generated by EphA/ephrin-A forward signaling. $(D)$ Depicted is the favored model to generate topographic-specific interstitial branching in the chick OT and mouse SC and is based on known activities (see text). Topographic-specific branching is generated by opposing gradients of branch inhibiting molecules combined with a branch promoting activity. In this model, the repellent gradient because of EphA/ephrin-A forward signaling inhibits branching posterior to the $\mathrm{TZ}$ and the repellent gradient because ephrin-A/EphA reverse signaling inhibits branching anterior to the TZ. Branching occurs preferentially at a trough in the opposing repellent gradients that is subthreshold for branch inhibition and is located at the correct AP position of the TZ. At the position of this trough, the activity of a branch promoter (such as BDNF signaling through TrkB) is suprathreshold for branch inhibition and generates branching at this topographically correct location for the TZ. The distributions of EphAs, ephrin-As, BDNF, and trkB in the retina and OT/SC, are appropriate for this model, and it is consistent with gain- and loss-of-function analyses of map development in chicks and mice. See Text for further description and references. (Modified from McLaughlin and O'Leary 2005 [ (C) Annual Reviews].) 
have shown that p75NTR is a coreceptor for ephrin-As, mediates the repellent effect of ephrin-A reverse signaling on RGC axons on binding EphAs, and is required for appropriate development of the retinotopic map in the SC (Lim et al. 2008).

The findings lead to the favored model for mapping, depicted in Figure 5D, that has at its primary foundation opposing gradients of repellents along the AP axis, one formed by EphA forward signaling that inhibits branching along the portion of RGC axons posterior to their correct $\mathrm{TZ}$ and the other formed by ephrin-A reverse signaling that inhibits branching along the portion of RGC axons anterior to their correct TZ. These opposing gradients of branch inhibitors cooperate with a branch-promoting activity (O'Leary et al. 1999; McLaughlin and O'Leary 2005; Lim et al. 2008). This branch promoting activity could be accomplished most simply by a branch promoter that is expressed uniformly along the AP axis, with branching preferentially allowed in a trough of the opposing repellents, which would have a unique AP position for each population of RGC axons defined by their TN origin (Fig. 5D). As described above, evidence suggests that BDNF expressed in the target is a branch promoter through activation of TrkB receptors on RGC axons.

Of course this model does not work in isolation as mapping is more complicated and clearly plastic. Other mechanisms work within this molecular framework to modify it and to influence map development. For example, as discussed earlier, a strict matching of dual gradients cannot explain the results seen in mice that the relative, rather than the absolute levels of EphA signaling, are a critical parameter for mapping (Brown et al. 2000; Reber et al. 2004), and that axon-axon competition based on repellent molecular interactions has a significant role (Prestige and Willshaw 1975; Feldheim et al. 1998; Brown et al. 2000; Yates et al. 2004; Tsigankov and Koulakov 2006). Computational modeling has shown that axon-axon competitive interactions increase as the system develops, by increasing the levels and slope of the EphA-ephrin-A gradients through the elaboration of RGC axonal arbors themselves, and has a critical role in generating enhanced specificity in branching and drives remodeling through a mechanism involving an increase in EphA-ephrin-A repellent activities as the map develops (Yates et al. 2004). Because temporal axons are repelled from the posterior SC by ephrin-As, competition would be elevated in the anterior SC, providing an induced gradient of forces that would tend to drive axons with lower EphA expression in a posterior direction. Competition not only ensures that axons fill all of the available space, but also provides the force that counterbalances a repellent gradient of ephrin-As. Incorporating competition into a mapping model also explains why axons fill the entire SC in EphA and ephrin-A mutants, and is consistent with a large body of earlier work involving ablations of parts of the retina or tectum/SC in rodents (Finlay et al. 1979; Simon et al. 1994), amphibians and fish (Fraser and Hunt 1980). Those experiments indicated that, at least under some experimental conditions, retinal axons tend to spread out and fill the available space in the target.

\section{DORSAL-VENTRAL MAPPING: TOPOGRAPHIC GUIDANCE OF INTERSTITIAL BRANCHES}

The mapping of the TN and DV retinal axes onto the AP and ML axis of the OT/SC has historically been portrayed as a Cartesian mapping system. And although the final "map" can indeed be depicted in that fashion, the axon behaviors that map the two axes are entirely distinct, involve entirely different axonal behaviors, and therefore require distinct strategies and needs for topographic guidance molecules. This holds true for all model species, even though mapping in frogs and fish is distinct and "simple" relative to that in chicks and rodents. Unlike AP mapping, DV mapping is already established in part by the orderly arrangement of RGC axons within the optic tract prior to their entering the OT/SC, especially in frogs and fish, and subsequent mapping within the OT/SC of chicks and mice is accomplished by the bidirectional growth of primary interstitial branches along the DV (ML) axis. 
The use of interstitial branching to map the DV axis in chicks and mice requires the coordinated function of distinct molecular activities along both the AP and the DV (ML) axes of the OT/SC. Sometimes RGC axons from the same retinal location enter and grow across the OT/SC with a broad distribution over its LM axis, though biased for the LM location of their future TZ (Nakamura and O'Leary 1989; Simon and O'Leary 1991, 1992b,c; Hindges et al. 2002). Topographic specificity emerges through the bidirectional guidance along the DV (ML) axis of the primary interstitial branches that form along RGC axons with AP specificity (Nakamura and O'Leary 1989; Hindges et al. 2002; McLaughlin et al. 2003b). Branches that extend from RGC axons located lateral to their future TZ preferentially grow medially, whereas branches that extend from RGC axons located medial to their future TZ preferentially grow laterally (Nakamura and O'Leary 1989; Hindges et al. 2002; McLaughlin et al. 2003b). Although the initial budding of interstitial branches does not appear to be directionally biased, branches that bud toward the correct DV (ML) location of their future TZ preferentially elongate. The directional specificity of branch extension increases as branches extend along the ML axis: i.e., longer branches show a higher degree of topographically correct, directional extension (Yates et al. 2001). Those branches that reach the vicinity of the nascent TZ preferentially form complex arbors.

\section{EPHBs AND EPHRIN-Bs CONTROL DORSAL-VENTRAL MAPPING}

The molecular mechanisms that control DV mapping in chicks and mice can account for the bidirectional guidance along the ML axis of interstitial branches that extend from RGC axons that originate from the same retinal address, and therefore express the same set of receptors at similar levels. Studies of the molecular control of DV mapping in chick and mice have shown that EphB/ephrin-B signaling has bifunctional activities (i.e., repellent or attractant) that depends on ephrin-B concentration relative to EphB levels.
During map development in chicks and mice, ephrin-B1 is expressed in a low to high LM (VD) gradient in the OT/SC, whereas EphB2 and EphB3 are expressed by RGCs in a low to high DV gradient, and EphB1 in a roughly uniform pattern, resulting in an overall low to high DV gradient of EphB receptors (Fig. 3). Thus, on the basis of these expression patterns and mapping coordinates, EphB/ ephrin-B1 forward signaling would function as an attractant for RGC axons. Analyses of mice with targeted deletions of EphB2 and EphB3, with and without reverse signaling intact, show aberrant ML mapping with ectopic TZs that are always located lateral to the correct TZ (Hindges et al. 2002). A time-course of mapping in these mice shows that these ectopic TZs are formed because of substantial defects in the directional guidance of interstitial branches along the ML axis. Studies in chick using ectopic expression of ephrin-B1 in OT show that for a set of neighboring RGCs, interstitial branches that form from axons positioned lateral to their appropriate $\mathrm{TZ}$ are attracted up the ephrin-B1 gradient to their TZ, whereas interstitial branches that form from axons located medial to their appropriate $\mathrm{TZ}$ are repelled down the ephrin-B1 gradient to the TZ (McLaughlin et al. 2003b). Thus, neighboring RGCs that presumably express a near identical set of EphBs/ephrin-Bs respond to ephrin-B1 in the OT in a concentrationdependent manner, with higher levels of ephrin-B1 acting as a repellent and lower levels acting as an attractant.

This bifunctional action of ephrin-B1 through EphBs on RGC axons may be because of the balance of distinct responses through each receptor type (i.e., EphB2 signaling results in attraction and EphB1 in repulsion) or to a combinatorial thresh-holding mechanism in which the combined signaling through all EphBs results in either attraction or repulsion controlled by a transition between attraction and repulsion to ephrin-B1 that is balanced at the TZ, and dependent on the concentration (level) of ephrin-B1 at the point where the branch forms on the parent RGC axon (Hindges et al. 2002; McLaughlin et al. 2003b). The 
findings from a recent study designed to help dissociate between these models show that EphB1, B2 and B3 have similar effects on branch guidance (attraction vs. repulsion), ruling out different effects assigned to different receptors, and thereby supporting the thresholding model (McLaughlin et al. 2009). Possible contributing factors include trans-endocytosis of EphBs and ephrin-Bs, which has been implicated in axon behavior switching from attraction to repulsion (Marston et al. 2003; Zimmer et al. 2003): Interpreting RGC axon behavior in the context of these findings suggest that at signaling levels above threshold, endocytosis and repulsion are favored whereas at low signaling levels endocytosis is diminished and attraction is favored.

In frogs, ephrin-B reverse signaling has a role in DV retinotopic mapping (Mann et al. 2002). It is not clear though whether this mechanism normally functions within the OT or alternatively within the optic pathway to establish a DV axial ordering of RGC axons within the optic tract that the axons retain as they enter the OT. The molecular framework for ephrin-B1 reverse signaling is present in chick and mice, as the overall low to high DV graded expression of EphBs by RGCs and the low to high LM (VD) of ephrin-B1 in the OT/SC are complemented by an opposing high to low DV gradient of ephrin-B1 by RGCs and an overall high to low LM gradient of EphBs in the OT/SC (Braisted et al. 1997; Hindges et al. 2002; McLaughlin et al. 2003b). A role for reverse signaling has been addressed in mice by replacing EphB2 with a kinase dead form thereby leaving reverse signaling intact but eliminating forward signaling; however, the EphB2 null phenotype was recapitulated in these mutants suggesting reverse signaling is not important for DV mapping in mice (Hindges et al. 2002).

EphB1, B2, B3 triple mutant mice do not show a complete absence of topography along the ML axis (McLaughlin et al. 2009); therefore other mechanisms must contribute to mapping this axis. One possibility is Wnt signaling (Schmitt et al. 2006). Wnt3 is expressed in a high to low ML gradient in chick OT and mouse SC, and members of the Ryk and Frizzled families of Wnt receptors are expressed in an overall high to low VD gradient by RGCs (Fig. 3). Functional studies show that Ryk mediates RGC axon repulsion by higher levels of Wnt3, whereas Frizzled receptors mediate an attractant effect of lower levels of Wnt3 on dorsal RGC axons. Thus, Wnt 3 , which is classically known as a secreted, diffusible signaling molecule, may act as a topographic guidance molecule in the OT and cooperate with EphB-ephrin-B1 signaling to regulate DV mapping.

\section{NEURAL ACTIVITY IS REQUIRED FOR FINE STRUCTURED TOPOGRAPHY}

Although it is clear that counter-balanced forces are used to specify topography, it is also clear that neural activity-dependent mechanisms are used in topographic map development. In activity-dependent mapping models, it is postulated that neurons with similar activity patterns are more likely to synapse on the same or adjacent target cells than are neurons with different activity patterns that are sufficiently distinct (Butts 2002; Debski and Cline 2002). Because the majority of topographic mapping in the visual system of mammals occurs before eye-opening, this mechanism is thought to rely on a type of spontaneous patterned retinal activity that propagates in the form of waves during the period of visual map formation (Feller et al. 1996; Penn et al. 1998; Shatz and Stryker 1988; Sretavan et al. 1988). Throughout the first postnatal week in mice, these waves are driven through a neural network of cholinergic amacrine cells and RGCs. In the absence of the $\beta 2$ subunit of the nicotinic acetylcholine receptor (nAChR), or in mice where retinal ACh transmission has been pharmacologically inhibited, waves during this stage are disrupted, resulting in RGC axon terminations in the SC and dLGN that are more diffuse than wild type terminations and also have topographic errors in each visual map (Feller et al. 1996; Rossi et al. 2001; Grubb et al. 2003; McLaughlin et al. 2003a; Cang et al. 2005b; Chandrasekaran et al. 2005; Pfeiffenberger et al. 2006).

Although retinal waves are important for topographic mapping, the mechanisms by which they act remain unclear. Neural activity could 
act in a Hebbian manner, such that neurons with similar, correlated activity patterns are more likely to synapse on the same target cells than are neurons with very different activity patterns that are sufficiently distinct to not be recognized as "correlated" patterns (Butts 2002; Debski and Cline 2002). Hebbian models predict that postsynaptic cells participate in mapping by rewarding correlated inputs or penalizing uncorrelated inputs. The moderate degree of disorder that persists in the retinotopic map in the SC of $\beta 2$ mutants shows that correlated activity patterns mediated by retinal waves are not required for large-scale remodeling, for example the elimination of temporal RGC axons from posterior SC (McLaughlin et al. 2003a). This was predicted by modeling of the relative contributions of molecular guidance information and patterned activity (Yates et al. 2004). These initial studies were extended by analysis of anatomical and functional maps in mice missing ephrin-As or $\beta 2$, or both ephrin-As and $\beta 2$ (Pfeiffenberger et al. 2006; Cang et al. 2008a,b). The findings suggest a mechanism whereby EphA/ephrin-A signaling acts to form "rough" topography, whereas neural activity acts to cluster correlated inputs to promote fine structure topography. In support of this two-step model, intrinsic optical imaging in ephrin-A2/A3/A5 triple mutant mice reveals that the functional map is discontinuous, with patches of SC responding to visual signals from topographically incorrect locations. Thus, in these mutants, large groups of neurons project together to topographically inappropriate locations. These clusters disappear in mice that are deficient in both ephrin-As and structured neural activity in the retina, leading to a nearly complete loss of topography along the $\mathrm{N}-\mathrm{T}$ axis of each visual area (Pfeiffenberger et al. 2006; Cang et al. 2008a,b). Thus correlated activity is required to cluster the axons of neighboring RGCs that project aberrantly in the absence of the contributions of ephrin-As at ectopic sites during map development. These comparisons show the relative contributions of molecular guidance information and correlated activity in both wild type and disorganized maps.
Although both ephrin-A- and activitydependent mechanisms are used to map visual projections, their relative contributions to forming functional maps seem to differ between the SC and V1. The removal of both ephrin-As and $\beta 2$-dependent activity results in a nearly complete absence of a map in both structures. However, the functional maps in V1 of ephrin-A mutants are not patchy, as they are in the SC, but blurry with normal global polarity (Cang et al. 2005a) whereas the functional maps in $\beta 2$ KOs are more diffuse in V1 than in SC (Cang et al. 2005b). This suggests that activity-dependent mechanisms may be able to more reliably silence the synapses of aberrant axons in the cortex than in SC. This could be because of the fact that geniculocortical synapses are more plastic than retinocollicular synapses, perhaps because of the longer lateral interactions predicted from modeling studies which show that global topography can be recovered in the absence of ephrin-As by increasing the range of activity-dependent interactions (Tsigankov and Koulakov 2006).

An interesting twist on the interplay between Eph/ephrin gradients and neural activity is shown in the projection between $\mathrm{V} 1$ and the $\mathrm{SC}$, a projection that is used to link the two major streams of visual processing. The V1-SC projection terminates in a deeper layer of the SC than retinal neurons and are organized such that they are in register with the retinocollicular map (Drager and Hubel, 1975). Using functional imaging, Triplett et al. (2009) found that the EphA3-KI mouse described above (Brown et al. 2000) has a duplicated retinocollicular map (Fig. 4) but a single functional map in V1. In these mice the corticocollicular projection now splits in two and aligns with both of the duplicated retinocollicular maps. These findings suggest that a retinal matching mechanism is used to map this projection. A time-course of the V1-SC projection shows that it occurs after the retinocollicular map is established but before eyeopening. Furthermore, the disruption of retinal waves in EphA3-ki mice prevents realignment. Therefore the V1-SC projection aligns with a pre-existing retinocollicular map (made 
by Eph/ephrins plus patterned activity) by matching activity patterns (Triplett et al. 2009).

\section{OTHER AXON GUIDANCE MOLECULES MAY BE IMPORTANT FOR TOPOGRAPHIC MAPPING}

Although EphA/ephrin-A and EphB/ephrin-B interactions are clearly required for topographic mapping, it is likely that other axon guidance molecules are also involved. In both ephrinA2/A3/A5 and EphB1/B2/B3 triple mutant mice, a number of RGCs do not make mapping errors. There could be two general reasons for this. Either each RGC is reading multiple cues, and sometimes the non-ephrin cues can substitute for their function, or it is possible that the ephrin dependent and independent RGCs represent different functional subtypes of RGCs.

There are multiple candidates for these missing activities, although their mechanism of action remains unclear. As described in preceding sections, Wnt3 and its receptors Ryk and Frizzled are reported to contribute to DV mapping in chick OT, and RGM and its receptor neogenin are potential topographic guidance molecules for the TN to AP axis. Mice mutant for the homophilic cell adhesion molecule L1 have topographic mapping defects along both axes of the SC (Demyanenko and Maness 2003). Remarkably, mice with a $\mathrm{Y} 1229 \mathrm{H}$ point mutation in the ankyrin binding region in $\mathrm{L} 1$ have mapping defects that are more constrained to just the $\mathrm{D}-\mathrm{V}$ mapping axis (Buhusi et al. 2008). The mechanism for L1 in mapping is unclear, but has been speculated to influence ephrin-A function. Multiple semaphorins and their receptors plexins and Neuropilins are expressed in the retina and tectum/SC during development, and Sema3A can repel Xenopus retinal axons in vitro (Campbell et al. 2001). In zebrafish, Sema3D is expressed more strongly in ventral than dorsal tectum and manipulation of Sema3D expression affects ventral RGCs more than dorsal RGCs (Liu et al. 2004). Interestingly Sema3D has been shown to regulate L1 protein levels on axons in other contexts and it is possible that a similar regulatory pathway is involved in visual mapping (Wolman et al. 2007). Other molecules that may be involved in topographic mapping are a secreted form of the transcription factor engrailed 2 (Brunet et al. 2005; Wizenmann et al. 2009), the highwire homologue Phr1, and the type 2 membrane protein Ten-M3 (also called ODZ3 and teneurin) (Oohashi et al. 1999).

Finally, another candidate for an AP mapping molecule is RGM (Repulsive Guidance Molecule) (Cox et al. 1990; Stahl et al. 1990), a $33 \mathrm{kDa}$, GPI-anchored protein expressed in the same graded pattern in the OT as ephrin-As (Müller et al. 1996). Recombinant RGM has a repellent effect selectively for chick temporal RGC axons (Monnier et al. 2002). RGM also repels the axons of chick RGCs transfected to express the RGM receptor neogenin (Rajagopalan et al. 2004). Perturbation of RGM levels in chick OT by overexpression or using RNAi disturbs the retinotectal projection in chicks (Matsunaga et al. 2006; Tassew et al. 2008). Further, the repellent effect of posterior OT membranes on temporal RGC axons is lost when RGM is "inactivated" using RGM-specific antibodies and the CALI (Chromophore Assisted Laser Inactivation) technique (Müller et al. 1996), albeit a curious finding because in principle the repellent activity of ephrin-As should persist. Therefore, RGM fulfills most of the criteria for it to be a topographic guidance molecule. However, targeted deletion of RGMa, one of three RGM family members in mice, but the closest homolog to chick RGM and the only one normally expressed in the SC, does not result in obvious defects in topographic mapping in the retinocollicular projection (Niederkofler et al. 2004). This lack of a defective mapping phenotype may be because of redundancy with RGMb or RGMc, with other mapping mechanisms (Matsunaga and Chedotal 2004; Niederkofler et al. 2004; Schmidtmer and Engelkamp 2004), or to a distinction in mechanisms and molecules between chicks and mice.

\section{CONCLUSIONS}

The discovery of Ephs and ephrins as topographic mapping molecules has facilitated research aimed to understand the mechanisms 
of topographic mapping. Use of in vitro assays and gain and loss of function analyses of Ephs and ephrins in cold and warm-blooded vertebrates has led to models that can explain how topographic maps form during development. Mapping mechanisms are more complex in warm-blooded vertebrates, with topographicspecific interstitial axon branching as a featured mechanism. Along each mapping axis dual gradients of axon guidance activity combined with axon competition and correlated neural activity are used to specify axonal branch points, guide the branches, and refine their terminations. Future directions include understanding the signaling pathways used to execute Eph/ephrin signaling, interactions between these signaling systems and those of other guidance molecules as well as with neurotrophins and their receptors. Further, it will be of great interest to understand whether or not topographic mapping defects lead to changes in visual perception, how this outcome is achieved, and its behavioral consequences.

\section{ACKNOWLEDGMENTS}

We thank members of the Feldheim and O'Leary labs for contributing to work and concepts presented in this article, in particular Cory Pfeiffenberger, Ben Stafford, Jason Triplett, Yoo-Shick Lim and Todd McLaughlin. The work in the authors' labs on this topic is supported by NEI grants EYO14689 (DAF) and R01 EY07025 (DOL).

\section{REFERENCES}

Bastmeyer M, O’Leary DDM. 1996. Dynamics of target recognition by interstitial axon branching along developing cortical axons. J Neurosci 16: 1450-1459.

Braisted JE, McLaughlin T, Wang HU, Friedman GC, Anderson DJ, O’Leary DDM. 1997. Graded and lamina-specific distributions of ligands of EphB receptor tyrosine kinases in the developing retinotectal system. Dev Biol 191: $14-28$

Brown A, Yates PA, Burrols P, Ortuno D, Vaidya A, Jessell TM, Pfaff SL, O’Leary DDM, Lemke G. 2000. Topographic mapping from the retina to the midbrain is controlled by relative but not absolute levels of EphA receptor signaling. Cell 102: 77-88.
Brunet I, Weinl C, Piper M, Trembleau A, Volovitch M, Harris W, Prochiantz A, Holt C. 2005. The transcription factor Engrailed-2 guides retinal axons. Nature 438: 94-98.

Buhusi M, Schlatter MC, Demyanenko GP, Thresher R, Maness PF. 2008. L1 interaction with ankyrin regulates mediolateral topography in the retinocollicular projection. J Neurosci 28: 177-188.

Butts DA. 2002. Retinal waves: implications for synaptic learning rules during development. Neuroscientist 8: $243-253$.

Campbell DS, Regan AG, Lopez JS, Tannahill D, Harris WA \& Holt CE. 2001. Semaphorin 3A elicits stage-dependent collapse, turning, and branching in Xenopus retinal growth cones. J Neurosci 21: 8538-8547.

Cang J, Kaneko M, Yamada J, Woods G, Stryker MP, Feldheim DA. 2005a. Ephrin-as guide the formation of functional maps in the visual cortex. Neuron 48: 577-589.

Cang J, Niell CM, Liu X, Pfeiffenberger C, Feldheim DA, Stryker MP. 2008a. Selective disruption of one Cartesian axis of cortical maps and receptive fields by deficiency in ephrin-As and structured activity. Neuron 57: 511-523.

Cang J, Renteria RC, Kaneko M, Liu X, Copenhagen DR Stryker MP. 2005b. Development of precise maps in visual cortex requires patterned spontaneous activity in the retina. Neuron 48: 797-809.

Cang J, Wang L, Stryker MP, Feldheim DA. 2008b. Roles of ephrin-as and structured activity in the development of functional maps in the superior colliculus. J Neurosci 28: 11015-11023.

Chandrasekaran AR, Plas DT, Gonzalez E, Crair MC. 2005. Evidence for an instructive role of retinal activity in retinotopic map refinement in the superior colliculus of the mouse. J Neurosci 25: 6929-6938.

Cheng HJ, Flanagan JG. 1994. Identification and cloning of ELF-1, a developmentally expressed ligand for the Mek4 and Sek receptor tyrosine kinases. Cell 79: 157-168.

Cheng HJ, Nakamoto M, Bergemann AD, Flanagan JG. 1995. Complementary gradients in expression and binding of ELF-1 and Mek4 in development of the topographic retinotectal projection map. Cell 82: 371-381.

Choi O, O'Leary DDM. 2000. Potential roles for BDNF and TrkB in developing topographic retinotectal projections. Soc Neurosci Abstr 26.

Choi SB, Yates PA, O’Leary DDM. 1998. Localized BDNF application induces branch-like structures along retinal axons. Soc Neurosci Abstr 24.

Cox EC, Muller B, Bonhoeffer F. 1990. Axonal guidance in the chick visual system: posterior tectal membranes induce collapse of growth cones from the temporal retina. Neuron 4: 31-37.

Debski EA, Cline HT. 2002. Activity-dependent mapping in the retinotectal projection. Curr Opin Neurobiol 12: 93-99.

Demyanenko GP, Maness PF. 2003. The L1 cell adhesion molecule is essential for topographic mapping of retinal axons. J Neurosci 23: 530-538.

Drager UC, Hubel DH. 1975. Responses to visual stimulation and relationship between visual, auditory, and somatosensory inputs in mouse superior colliculus. $J$ Neurophysiol 38: 690-713 
D.A. Feldheim and D.D.M. O'Leary

Drescher U, Kremoser C, Handwerker C, Loschinger J, Noda M, Bonhoeffer F. 1995. In vitro guidance of retinal ganglion cell axons by RAGS, a $25 \mathrm{kDa}$ tectal protein related to ligands for Eph receptor tyrosine kinases. Cell 82: 359-370.

Egea J, Klein R. 2007. Bidirectional Eph-ephrin signaling during axon guidance. Trends Cell Biol 17: 230-238.

Eph Nomenclature Committee. 1997. Unified nomenclature for Eph family receptors and their ligands, the ephrins. Cell 8: 403-404.

Feldheim DA, Kim Y, Bergemann AD, Frisen J, Barbacid M, Flanagan JG. 2000. Genetic analysis of ephrin-A2 and ephrin-A5 shows their requirement in multiple aspects of retinocollicular mapping. Neuron 25: 563-574.

Feldheim DA, Nakamoto M, Osterfield M, Gale NW, DeChiara TM, et al. 2004. Loss-of-function analysis of EphA receptors in retinotectal mapping. J Neurosci 24: 2542-2450.

Feldheim DA, Vanderhaeghen P, Hansen MJ, Frisen J, Lu Q, Barbacid M., Flanagan JG. 1998 Topographic guidance labels in a sensory projection to the forebrain. Neuron 21: $1303-1313$.

Feller MB, Wellis DP, Stellwagen D, Werblin FS, Shatz CJ. 1996. Requirement for cholinergic synaptic transmission in the propagation of spontaneous retinal waves. Science 272: $1182-1187$.

Finlay BL, Schneps SE, Schneider GE. 1979. Orderly compression of the retinotectal projection following partial tectal ablation in the newborn hamster. Nature 280: 153-155.

Fraser SE, Hunt RK. 1980. Retinotectal specificity: Models and experiments in search of a mapping function. Ann Rev Neurosci 3: 319-352.

Frisen J, Yates PA, McLaughlin T, Friedman GC, O'Leary DDM, Barbacid M. 1998. Ephrin-A5 (AL-1/RAGS) is essential for proper retinal axon guidance and topographic mapping in the mammalian visual system. $\mathrm{Neu}$ ron 20: $235-243$.

Fujisawa H. 1987. Axonal growth in developing and regenerating amphibian retinotectal projection. Prog Brain Res 71: 75-88.

Grubb MS, Rossi FM, Changeux JP, Thompson ID. 2003. Abnormal functional organization in the dorsal lateral geniculate nucleus of mice lacking the $\beta 2$ subunit of the nicotinic acetylcholine receptor. Neuron 40: 1161-1172.

Hansen MJ, Dallal GE, Flanagan JG. 2004. Retinal axon response to ephrin-as shows a graded, concentrationdependent transition from growth promotion to inhibition. Neuron 42: 717-730.

Harris WA, Holt CE, Bonhoeffer F. 1987. Retinal axons with and without their somata, growing to and arborizing in the tectum of Xenopus embryos: a time-lapse video study of single fibres in vivo. Development 101: $123-133$.

Hindges R, McLaughlin T, Genoud N, Henkemeyer M, O’Leary DDM. 2002. EphB forward signaling controls directional branch extension and arborization required for dorsal ventral retinotopic mapping. Neuron 35: $475-487$.
Hoopfer ED, McLaughlin T, Watts RJ, Schuldiner O, O'Leary DDM, Luo L. 2006. Wlds protection distinguishes axon degeneration following injury from naturally-occurring developmental pruning. Neuron 50: 883-895.

Kaethner RJ, Stuermer CA. 1992. Dynamics of terminal arbor formation and target approach of retinotectal axons in living zebrafish embryos: a time-lapse study of single axons. J Neurosci 12: 3257-3271.

Kullander K, Klein R. 2002 Mechanisms and functions of Eph and ephrin signalling. Nat Rev Mol Cell Biol 3: 475-486.

Lim Y-S, McLaughlin T, Sung T-C, Santiago A, Lee K-F, O'Leary DDM. 2008 p75NTR mediates ephrin-A reverse signaling required for axon repulsion and mapping. Neuron 59: 746-758.

Lewin B. 1994. On neuronal specificity and the molecular basis of perception. Cell 79: 935-943.

Liu Y, Berndt J, Su F, Tawarayama H, Shoji W, Kuwada JY, Halloran MC. 2004. Semaphorin3D guides retinal axons along the dorsoventral axis of the tectum. J Neurosci 24: 310-318.

Mann F, Ray S, Harris WA, Holt CE. 2002. Topographic mapping in dorsoventral axis of the Xenopus retinotectal system depends on signaling through ephrin-B ligands. Neuron 35: 461-473.

Marquardt T, Shirasaki R, Ghosh S, Andrews SE, Carter N, Hunter T, Pfaff SL. 2005. Coexpressed EphA receptors and ephrin-A ligands mediate opposing actions on growth cone navigation from distinct membrane domains. Cell 121: 127-139.

Marston DJ, Dickinson S, Nobes CD. 2003. Rac-dependent trans-endocytosis of ephrinBs regulates Eph-ephrin contact repulsion. Nat Cell Biol 5: 879-888.

Matsunaga E, Chedotal A. 2004. Repulsive guidance molecule/neogenin: A novel ligand-receptor system playing multiple roles in neural development. Dev Growth Differ 46: 481-486.

Matsunaga E, Nakamura H, Chedotal A. 2006 Repulsive guidance molecule plays multiple roles in neuronal differentiation and axon guidance. $J$ Neurosci 26: 6082-6088.

McLaughlin T, O'Leary DDM. 2005. Molecular gradients and development of retinotopic maps. Ann Rev Neurosci 28: $327-356$.

McLaughlin T, Hindges R, O’Leary DDM. 2003c. Regulation of axial patterning of the retina and its topographic mapping in the brain. Curr Op Neurobio 13: 57-69.

McLaughlin T, Hindges R, Yates PA, O'Leary DDM. 2003b. Bifunctional action of ephrin-B1 as a repellent and attractant to control bidirectional branch extension in dorsal-ventral retinotopic mapping. Development 130: 2407-2418.

McLaughlin T, Lim Y-S, Santiago A, O'Leary DDM. 2009. EphB receptors in retinal ganglion cells direct dorsalventral retinotopic mapping by specific guidance of branches. Soc Neurosci Abstr 35.

McLaughlin T, Torgorg CL, Feller MB, O'Leary DDM. 2003a. Retinotopic map refinement requires spontaneous retinal waves during a brief critical period of development. Neuron 40: 1147-1160. 
Monnier PP, Sierra A, Macchi P, Deitinghoff L, Andersen JS et al. 2002. RGM is a repulsive guidance molecule for retinal axons. Nature 419: 392-395.

Monschau B, Kremoser C, Ohta K, Tanaka H, Kaneko T, et al. 1997. Shared and distinct functions of RAGS and ELF-1 in guiding retinal axons. EMBO J 16: 1258-1267.

Müller BK, Jay DG, Bonhoeffer F. 1996. Chromophoreassisted laser inactivation of a repulsive axonal guidance molecule. Curr Biol 6: 1497-1502.

Nakamoto M, Cheng HJ, Friedman GC, McLaughlin T, Hansen MJ, et al. 1996. Topographically specific effects of ELF-1 on retinal axon guidance in vitro and retinal axon mapping in vivo. Cell 86: 755-766.

Nakamura H, O'Leary DDM. 1989. Inaccuracies in initial growth and arborization of chick retinotectal axons followed by course corrections and axon remodeling to develop topographic order. J Neurosci 9: 3776-3795.

Niederkofler V, Salie R, Sigrist M, Arber S. 2004. Repulsive guidance molecule (RGM) gene function is required for neural tube closure but not retinal topography in the mouse visual system. J Neurosci 24: 808-818.

Nikolaev A, McLaughlin T, O'Leary DDM, Tessier-Lavinge M. 2009. APP binds DR6 to trigger axon pruning and neuron death via distinct caspases. Nature 457: 981-990.

O'Leary DDM, Fawcett JW, Cowan WM. 1986. Topographic targeting errors in the retinocollicular projection and their elimination by selective ganglion cell death. J Neurosci 6: 3692-3705.

O’Leary DDM, Yates P, McLaughlin T. 1999. Mapping sights and smells in the brain: Distinct mechanisms to achieve a common goal. Cell 96: 255-269.

O’Rourke NA, Fraser SE. 1990. Dynamic changes in optic fiber terminal arbors lead to retinotopic map formation: an in vivo confocal microscopic study. Neuron 5: 159-171.

Oohashi T, Zhou XH, Feng K, Richter B, Morgelin M, Perez MT, SU WD, Chiquet-Ehrismann R, Rauch U, Fassler R. 1999. Mouse ten-m/Odz is a new family of dimeric type II transmembrane proteins expressed in many tissues. J Cell Biol 145: 563-577.

Penn AA, Riquelme PA, Feller MB, Shatz CJ. 1998 Competition in retinogeniculate patterning driven by spontaneous activity. Science 279: 2108-2112.

Pfeiffenberger C, Yamada J, Feldheim DA. 2006. Ephrin-As and patterned retinal activity act together in the development of topographic maps in the primary visual system. J Neurosci 26: 12873-12884.

Prestige MC, Willshaw DJ. 1975. On a role for competition in the formation of patterned neural connexions. Proc $R$ Soc Lond B 190: 77-98.

Rajagopalan S, Deitinghoff L, Davis D, Conrad S, Skutella T, et al. 2004. Neogenin mediates the action of repulsive guidance molecule. Nat Cell Biol 6: 756-762.

Rashid T, Upton AL, Blentic A, Ciossek T, Knoll B, Thompson ID, Drescher U. 2005. Opposing gradients of ephrin-As and EphA7 in the superior colliculus are essential for topographic mapping in the mammalian visual system. Neuron 47: 57-69.

Reber M, Burrola P, Lemke G. 2004. A relative signalling model for the formation of a topographic neural map. Nature 431: 847-853.
Roskies AL, O’Leary DDM. 1994. Control of topographic retinal axon branching by inhibitory membrane-bound molecules. Science 265: 799-803.

Rossi FM, Pizzorusso T, Porciatti V, Marubio LM, Maffei L, Changeux JP. 2001. Requirement of the nicotinic acetylcholine receptor $\beta 2$ subunit for the anatomical and functional development of the visual system. Proc Natl Acad Sci USA 98: 6453-6458.

Sakurai T, Wong E, Drescher U, Tanaka H, Jay DG. 2002. Ephrin-A5 restricts topographically specific arborization in the chick retinotectal projection in vivo. Proc Natl Acad Sci 99: 10795-10800.

Schmidtmer J, Engelkamp D. 2004. Isolation and expression pattern of three mouse homologues of chick Rgm. Gene Expr Patterns 4: 105-110.

Schmitt AM, Shi J, Wolf AM, Lu CC, King LA, Zou Y. 2006. Wnt-Ryk signalling mediates medial-lateral retinotectal topographic mapping. Nature 439: 31-37.

Shatz CJ, Stryker MP. 1988 Prenatal tetrodotoxin infusion blocks segregation of retinogeniculate afferents. Science, 242: $87-89$.

Simon DK, O'Leary DDM. 1990. Limited topographic specificity in the targeting and branching of mammalian retinal axons. Develop Biol 137: 125-134.

Simon DK, O'Leary DDM. 1991. Relationship of retinotopic ordering of axons in the optic pathway to the formation of visual maps in central targets. J Comp Neurol 307: 393-404.

Simon DK, O'Leary DDM. 1992a. Responses of retinal axons in vivo and in vitro to position-encoding molecules in the embryonic superior colliculus. Neuron 9: 977-989.

Simon DK, O'Leary DDM. 1992b. Development of topographic order in the mammalian retinocollicular projection. J Neurosci 12: 1212-1232

Simon DK, O'Leary DDM. 1992c. Influence of position along the medial-lateral axis of the superior colliculus on the topographic targeting and survival of retinal axons. Dev Brain Res 69: 167-172.

Simon DK, Roskies AL, O'Leary DDM. 1994. Plasticity in the development of topographic order in the mammalian retinocollicular projection. Dev Biol 162: 384-393.

Sperry RW. 1951. Regulative factors in the orderly growth of neural circuits. Growth 15: 63-87.

Sperry R. 1963. Chemoaffinity in the orderly growth of nerve fiber patterns and connections. Proc Natl Acad Sci 50: 703-710.

Stahl B, Muller B, von Boxberg Y, Cox EC, Bonhoeffer F. 1990. Biochemical characterization of a putative axonal guidance molecule of the chick visual system. Neuron 5: 735-743.

Sretavan DW, Shatz CJ, Stryker MP. 1988. Modification of retinal ganglion cell axon morphology by prenatal infusion of tetrodotoxin. Nature 336: 468-471.

Tassew NG, Chestopolava L, Beecroft R, Matsunaga E, Teng H, Chedotal A, Monnier PP. 2008. Intraretinal RGMa is involved in retino-tectal mapping. Mol Cell Neurosci 37: 761-769.

Torii M, Levitt P. 2005. Dissociation of corticothalamic and thalamocortical axon targeting by an EphA7-mediated mechanism. Neuron 48: 563-575. 
D.A. Feldheim and D.D.M. O'Leary

Triplett JW, Owens MT, Yamada J, Lemke G, Cang J, Stryker MP, Feldheim DA. 2009. Retinal input instructs alignment of visual topographic maps. Cell 139: 175-185.

Tsigankov DN, Koulakov AA. 2006. A unifying model for activity-dependent and activity-independent mechanisms predicts complete structure of topographic maps in ephrin-A deficient mice. J Comput Neurosci 21: $101-114$.

Udin SB, Fawcett JW. 1988. Formation of topographic maps. Ann Rev Neurosci 11: 289-327.

Walter J, Henke-Fahle S, Bonhoeffer F. 1987a. Avoidance of posterior tectal membranes by temporal retinal axons. Development 101: 909-913.

Walter J, Kern-Veits B, Huf J, Stolze B, Bonhoeffer F. 1987b. Recognition of position-specific properties of tectal cell membranes by retinal axons in vitro. Development 101: 685-696.

Wizenmann A, Brunet I, Lam J.S, Sonnier L, Beurdeley M, Zarbalis K, Weisenhorn-Vogt D, Weinl C, Dwivedy A,
Joliot A, et al. 2009. Extracellular Engrailed participates in the topographic guidance of retinal axons in vivo. Neuron 64: 355-366.

Wolman MA, Regnery AM, Becker T, Becker CG, Halloran MC. 2007. Semaphorin3D regulates axon axon interactions by modulating levels of L1 cell adhesion molecule. J Neurosci 27: 9653-9663.

Yates PA, Holub AD, McLaughlin T, Sejnowski TJ, O’Leary DDM. 2004. Computational modeling of retinotopic map development to define contributions of EphA-ephrinA gradients, axon-axon interactions, and patterned activity. J Neurobiol 59: 95-113.

Yates PA, Roskies AR, McLaughlin T, O’Leary DDM. 2001. Topographic specific axon branching controlled by ephrin-As is the critical event in retinotectal map development. J Neurosci 21: 8548-8563.

Zimmer M, Palmer A, Kohler J, Klein R. 2003. EphBephrinB bi-directional endocytosis terminates adhesion allowing contact mediated repulsion. Nat Cell Biol 5: 869-878. 


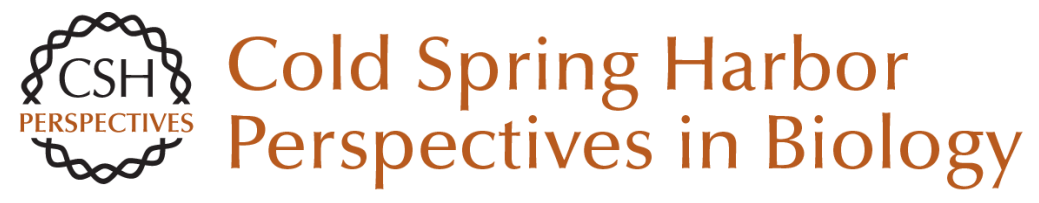

\title{
Visual Map Development: Bidirectional Signaling, Bifunctional Guidance Molecules, and Competition
}

\author{
David A. Feldheim and Dennis D. M. O'Leary
}

Cold Spring Harb Perspect Biol 2010; doi: 10.1101/cshperspect.a001768 originally published online September 29, 2010

\section{Subject Collection Neuronal Guidance}

Mechanisms and Molecules of Neuronal Wiring: A

Primer

Alex L. Kolodkin and Marc Tessier-Lavigne

Guidance Molecules in Axon Pruning and Cell

Death

Pierre Vanderhaeghen and Hwai-Jong Cheng

Initiating and Growing an Axon

F. Polleux and William Snider

Navigating Intermediate Targets: The Nervous

System Midline

Barry J. Dickson and Yimin Zou

Cellular Strategies of Axonal Pathfinding

Jonathan Raper and Carol Mason

Guidance Molecules in Axon Regeneration Roman J. Giger, Edmund R. Hollis II and Mark H. Tuszynski

Signaling from Axon Guidance Receptors Greg J. Bashaw and Rüdiger Klein

Visual Map Development: Bidirectional Signaling, Bifunctional Guidance Molecules, and Competition

David A. Feldheim and Dennis D. M. O'Leary
Wiring the Brain: The Biology of Neuronal

Guidance

Alain Chédotal and Linda J. Richards

Guidance Molecules in Synapse Formation and

Plasticity

Kang Shen and Christopher W. Cowan

The Growth Cone Cytoskeleton in Axon

Outgrowth and Guidance

Erik W. Dent, Stephanie L. Gupton and Frank B. Gertler

Topographic Mapping--The Olfactory System Takeshi Imai, Hitoshi Sakano and Leslie B. Vosshall

Self-avoidance and Tiling: Mechanisms of

Dendrite and Axon Spacing

Wesley B. Grueber and Alvaro Sagasti

Trafficking Guidance Receptors

Bettina Winckler and Ira Mellman

Axon Guidance Molecules in Vascular Patterning Ralf $\mathrm{H}$. Adams and Anne Eichmann

Human Genetic Disorders of Axon Guidance Elizabeth C. Engle

For additional articles in this collection, see http://cshperspectives.cshlp.org/cgi/collection/

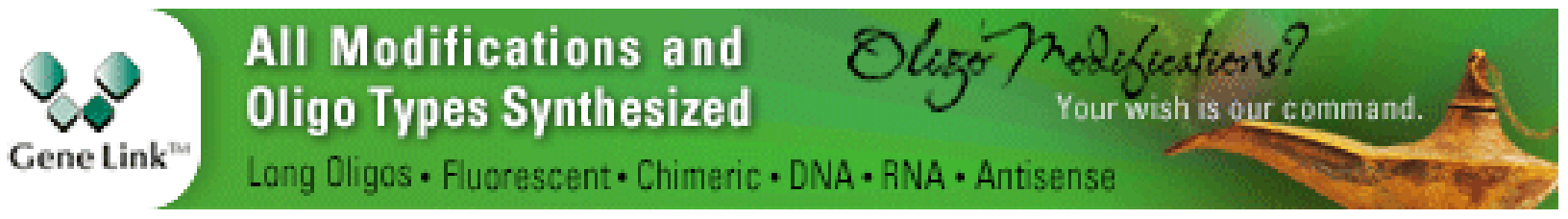

